\title{
Towards a skills taxonomy for a multinational energy technology company
}

Citation for published version (APA):

Fouarge, D., \& Steens, S. (2021). Towards a skills taxonomy for a multinational energy technology company. ROA. ROA Reports No. 008 https://doi.org/10.26481/umarep.2021008

Document status and date:

Published: 19/11/2021

DOI:

10.26481/umarep.2021008

Document Version:

Publisher's PDF, also known as Version of record

\section{Please check the document version of this publication:}

- A submitted manuscript is the version of the article upon submission and before peer-review. There can be important differences between the submitted version and the official published version of record.

People interested in the research are advised to contact the author for the final version of the publication, or visit the DOI to the publisher's website.

- The final author version and the galley proof are versions of the publication after peer review.

- The final published version features the final layout of the paper including the volume, issue and page numbers.

Link to publication

\footnotetext{
General rights rights.

- You may freely distribute the URL identifying the publication in the public portal. please follow below link for the End User Agreement:

www.umlib.nl/taverne-license

Take down policy

If you believe that this document breaches copyright please contact us at:

repository@maastrichtuniversity.nl

providing details and we will investigate your claim.
}

Copyright and moral rights for the publications made accessible in the public portal are retained by the authors and/or other copyright owners and it is a condition of accessing publications that users recognise and abide by the legal requirements associated with these

- Users may download and print one copy of any publication from the public portal for the purpose of private study or research.

- You may not further distribute the material or use it for any profit-making activity or commercial gain

If the publication is distributed under the terms of Article $25 \mathrm{fa}$ of the Dutch Copyright Act, indicated by the "Taverne" license above, 
Maastricht University

\section{Towards a Skills Taxonomy for a Multinational Energy Technology Company}

Didier Fouarge

Sanne Steens

\section{ROA Report}

ROA-R-2021/8

Researchcentrum voor Onderwijs en Arbeidsmarkt | ROA Research Centre for Education and the Labour Market / ROA 


\section{Colophon}

(c) Research Centre for Education and the Labour Market (ROA). No part of this publication may be reproduced without the prior permission in writing of the director of the Research Centre for Education and the Labour Market.

\section{Research Centre for Education and the Labour Market}

P.O. Box 616

NL-6200 MD Maastricht

$\mathrm{T}+31433883647$

secretary-roa-sbe@maastrichtuniversity.nl

www.roa.nl

School of Business and Economics

Maastricht University

\section{Layout}

ROA secretariat, Maastricht

ISBN: 978-90-5321-610-1

ISSN: 2666-8858

November 2021 


\section{Content}

\section{Page}

1 Urgency of the research 1

2 Approach 3

$\begin{array}{lll}3 & \text { Findings } & 7\end{array}$

Appendix A: Detailed approach $\quad 11$

Appendix B: First implementations at the company 17 



\section{Urgency of the research}

Due to digitalization and decarbonization, the jobs and the skills that are demanded for these jobs change rapidly over time. This leads to challenges related to reskilling and strategic workforce recruitment choices. In response to the transformation in the energy market, energy technology companies are streamlining and innovating their portfolio and products. This leads to significantly changing skill demands.

As part of its strategy to make its workforce ready for the future - i.e., having the right skills at the right place at the right time - a multinational energy technology company engaged in a research cooperation with the Research Centre for Education and Labour of Market Maastricht University School of Business and Economics for research in the field of reskilling, strategic workforce choices, future skills and structural change tackling challenges related to decarbonization \& digitalization.

Aim

In order to know the future skills needs, we first need to know what skills are needed today. The aim of the research - which was organized as a co-creation exercise with the company in question - we report on in this study was threefold:

1. To provide a systematic overview of the current skills demand at the company by identifying skills patterns in job vacancies.

2. To document to what extent vacancies for jobs result from replacement of personnel or job growth and document the distribution of internal versus external hires.

3. To provide a comprehensive skills framework and taxonomy of the most important skills for jobs at the company.

\section{What does the company learn from this?}

This project provides the company with three key output. First, using text description of past vacancies, dictionaries of skills description and input from interviews with HR practitioners (see Chapter 2 for description of our approach), we deliver a systematic overview of the top 20 most distinctive skills for each job-group at the company (e.g., Sales or Finance). This can be used by HR to 1) analyze what skills are currently asked in the recruitment process, 2) reflect on the extent to which such skills are in line with the 
company's requirements and 3) adjust future job descriptions in accordance to upcoming skills needs.

Second, the comprehensive skills framework and taxonomy we develop provides a widely used common language, developed at a high level of aggregation, which makes it implementable across all job-groups and business units at the company.

Third, this project informs HR on the nature of vacancies: 1) the extent to which they result from replacement of personnel or job growth (addition of new personnel for jobs in growing demand), and 2) the extent to which these are filled via internal versus external hires, hereby providing insights on what skills are available within the organization and what skills have to be acquired from outside.

\section{O*NET skills classification as an anchor}

In so doing, we take the $\mathrm{O}^{*}$ NET skills classification as our starting point, in which we anchor the skills patterns we derive from vacancies at the company. The O*NET skills taxonomy describes the knowledge, skills and abilities for thousands of occupations in the US (https://www.onetcenter.org). It is the most commonly used and overarching taxonomy of skills we are aware of. It is used in academic research to describe and understand the changing demand for skills ${ }^{1}$, in personnel planning ${ }^{2}$, and by international organization such as $\mathrm{OECD}^{3}$ and World Economic Forum. ${ }^{4}$

\section{Content of report}

In this report, we describe our approach for retrieving skills from the vacancy data at the multinational energy technology company, how to read the output we generated with our analyses, and how we come to a comprehensive skills framework (Chapter 2). We then report on the most distinctive skills per jobs (Chapter 3 ). As an additional output for the company, we delivered two accompanying datasets with extensive descriptions of skills per jobs and a comprehensive skills framework for use as part as their strategic HR policy.

Acemoglu, D., \& Restrepo, P. (2018). Automation and new tasks: The implications of the task content of production for labor demand. Journal of Economic Perspectives, 33(2), 3-30.

2 Converse, P., Oswadl, F., Gillespie, Field, K., \& Bizot, E. (2004). Matching individuals to occupations using abilities and the O*NET: Issues and an application in career guidance. Personnel Psychology, 57(2), 451-487.

3 Arntz, M., Gregory, T., \& Zierahn, U. (2016). The risk of automation for jobs in OECD countries: A comparative analysis.

4 World Economic Forum (2021). Building a Common Language for Skills at Work: A Global Taxonomy. http:// www3.weforum.org/docs/WEF_Skills_Taxonomy_2021.pdf 


\section{Approach}

The multinational energy technology company we conducted this research for currently has a catalogue where competencies are listed for each job-group. This is a very extensive catalogue with overlapping components, but that lacks a common language across jobs-groups and company units. With the new taxonomy we aim to create one common language that is future-oriented and company-specific. We aim to make the taxonomy as comprehensive as possible, while at the same time keeping the items generic enough such that they are applicable across the different job-groups and business areas.

\section{An extension of $O^{*} N E T$ for this multinational energy technology company}

O*NET distinguishes among six major skill categories (Basic Skills, Complex Problem Solving Skills, Resource Management Skills, Social Skills, System Skills and Technical skills). These skills fall apart in sub skill category, and then in specific skill category, which are described in the $\mathrm{O}^{*}$ NET classification. For example, technical skills fall apart in 7 sub skills. One such sub skill is technology design and it consists of two specific skills Design to cost, and Technology design. Technology design is then described as "Job requires generating or adapting equipment and technology to serve user needs".

With the O*NET as a starting point, we created a taxonomy that was further developed and specified based on the existing competency catalogue, expert interviews with the company's HR-managers and team-discussions. Based on the input that was received from these qualitative interviews, the taxonomy was expanded and altered. Additional categories such as Agile, Lean, Inclusion, Sustainability and Consultative selling were added, and descriptions were altered to make them more company-specific.

After expanding this taxonomy, the main skill categories are named Social, management and leadership skills, Analytical, creative thinking and problem solving skills, Resource management skills, Technical skills and Learning skills to encompass the subcategories. We add the category Personality traits to reflect the growing demand for soft skills in the economy. ${ }^{5}$ Appendix B gives a flavor of how this taxonomy looks like, and how it has been implemented in an interactive dashboard for use for HR purposes within the company.

5 Deming, D. J. (2017). The growing importance of social skills in the labor market. The Quarterly Journal of Economics, 132(4), 1593-1640. 


\section{Text-mining of vacancy text}

Using text-mining techniques, we scan the texts of all job vacancies posted by the company in the period October 2018 - October 2020, a database filled with 9.551 vacancies for 7.950 job openings. We do this to identify the skills mentioned in the job descriptions to unravel the current skills-needs. Job descriptions in vacancies do not always follow a well-structured pattern: they are composed of a lot of text, parts of which refer to the skills needed to perform the job. The challenge to the researcher is to identify these skills. Using O*NET as the starting point would not suit the purpose as the skills there are too generic compared to the skills in a specific company such as the company in question. The challenge for the researcher, then, is to infer the skills need from the text of job descriptions itself. When doing so, we are generally less interested in the parts of the vacancy text with general information about the company, but more interested in the information that is specific to job advertised. To merely measure how frequently certain words appear in a job description, would be insufficient, since the general information is often similar across multiple vacancies. To circumvent this issue, we use text mining analysis on the vacancy texts, to extract the most distinctive skills for each jobgroup. ${ }^{6}$ Skills are identified as pairs of words from the vacancies that we have matched to a lexicon of skills. We use a statistical measure to identify these most distinctive skills. This statistical measure is the frequency of a term (pair of terms in our case) adjusted for how rarely it is used in the complete set of vacancy texts. Then, for each job-group, we manually label the top 20 skills identified by us with one of the main skills categories we adapted from the $\mathrm{O}$ *NET taxonomy.

\section{Co-creation taxonomy categories}

The outcomes for each job-group were checked by representatives from the company, and if necessary adjusted to ensure that all skills are labelled with the correct category. As a result, the category Learning Skills was included in the category Analytical, creative thinking and problem solving skills. Some representatives chose to assign certain skills to a different category, because in the context of their respective job-group it better fits to the skills needs as they see it. This final classification is used for shaping our output.

\section{Example outcome}

An example of the results can be found in Figure 1 where we describe the 20 most distinctive skills for 'site engineering' jobs. Two of the most distinctive skills pertain to working independently, which is part of personality traits in O*NET (purple colored). 10 of the top 20 most distinctive skills for site engineering pertain to the technical domain (yellow colored).

6 See Appendix A for details on the methodology we used. 
Figure 1 Site Engineering. Top 20 skills with a link to the taxonomy

Site Engineering- Distinctiveness (TF-IDF)

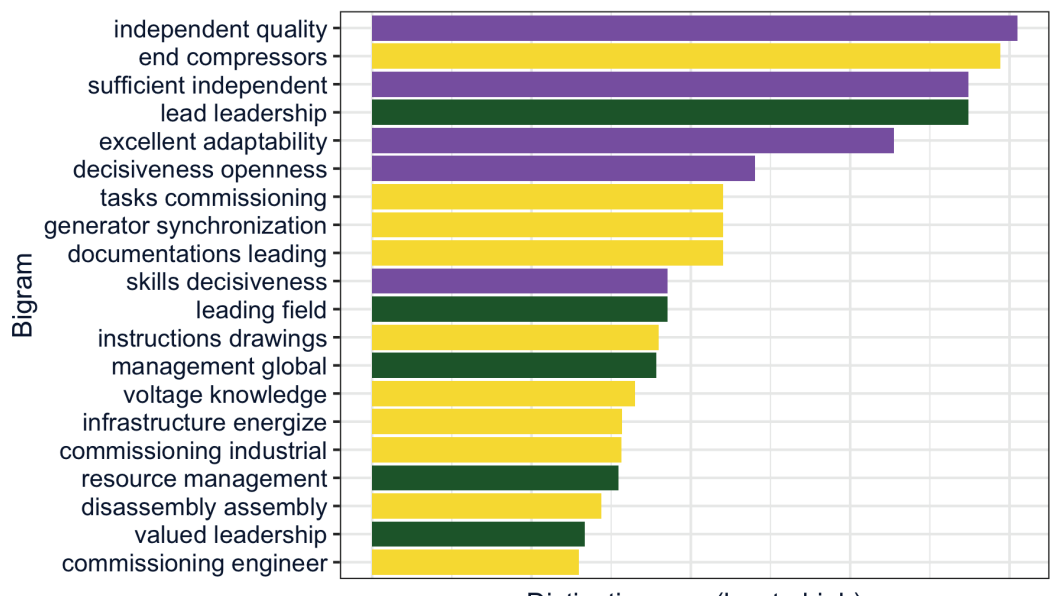

Distinctiveness (low to high)

Taxonomy category

Social, management and leadership skills

Technical skills

Personality traits 



\section{Findings}

In this chapter all findings are presented. We first display the skill demand at the company as they appear in vacancies and according to the classification we developed. For 5 job-group we display the top 20 most distinctive skills. Here, we display the job-groups Customer Services - Service Operations \& Delivery, Engineering - General Engineering, Finance - Accounting, Information Technology - General IT Management and Manufacturing - Process Planning \& Industrial Engineering. The complete set of all job-groups was provided to the company. Then, we discuss the extent to which vacancies results from replacement of personnel or job growth and document the distribution of internal versus external hires. All details are provided to the company in our supplementary material.

\section{Skills in jobs}

The top 20 most distinctive skills found in the job descriptions for the 5 job groups are represented in the graphs below. As these speak for themselves, we do not provide for an extensive description of what the graphs show, but it is clear that they show a great variety of skills both within and across jobs.

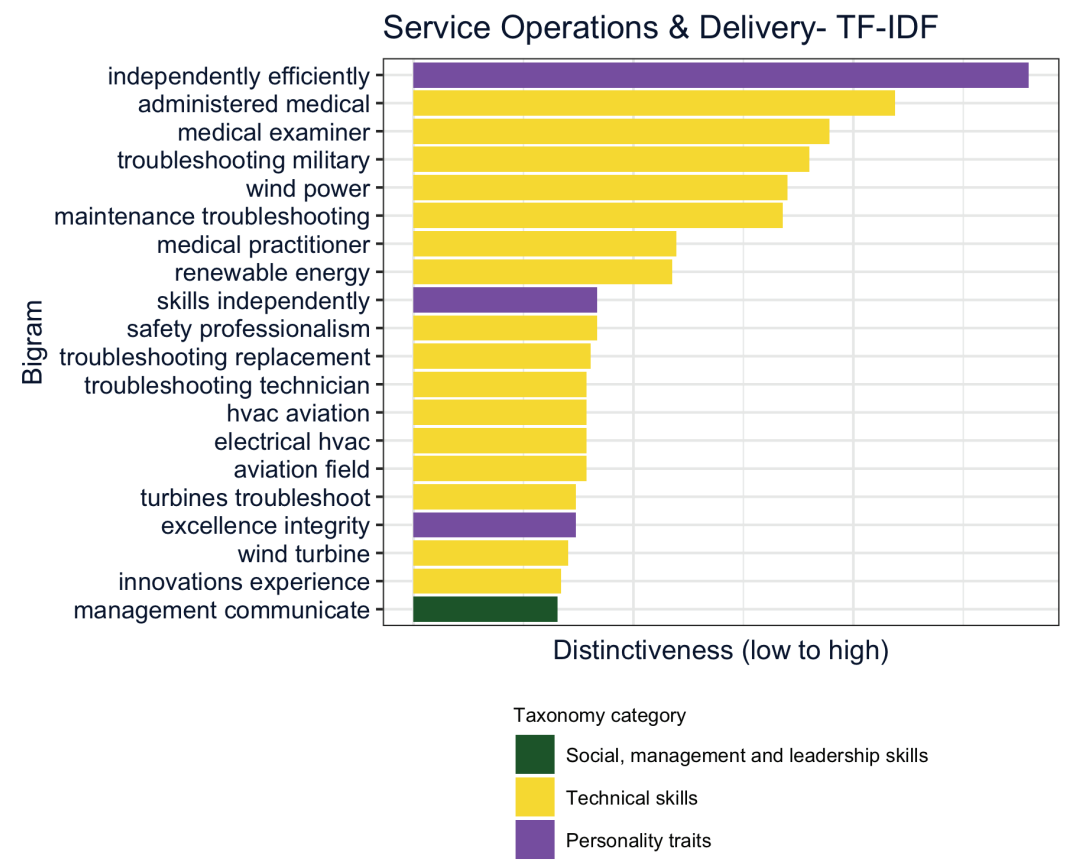




\section{Engineering - General Engineering}

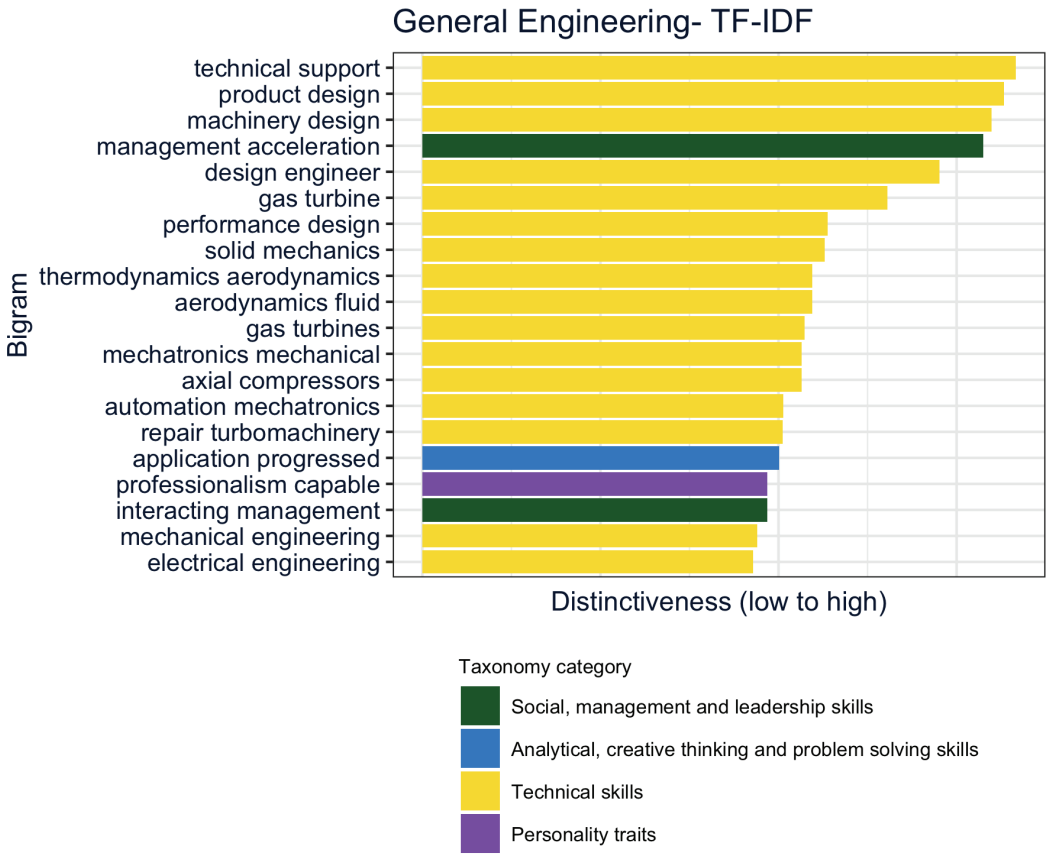

Finance - Accounting

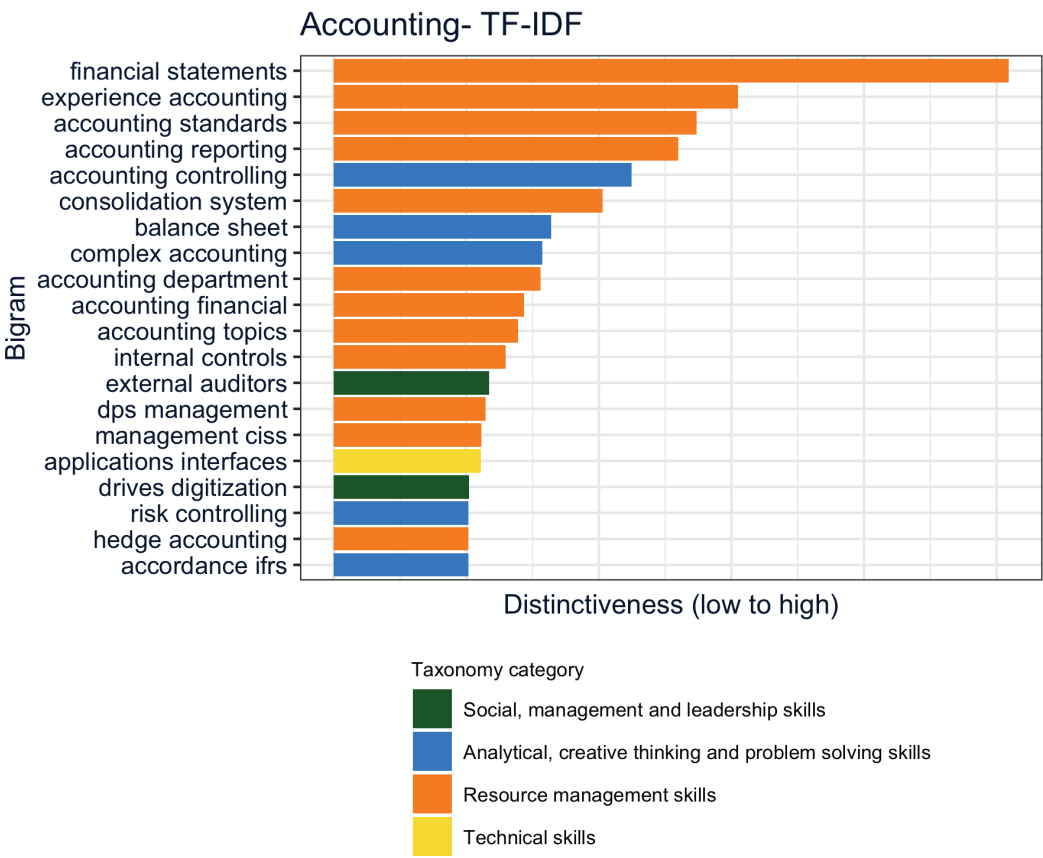




\section{Information Technology - General IT Management}

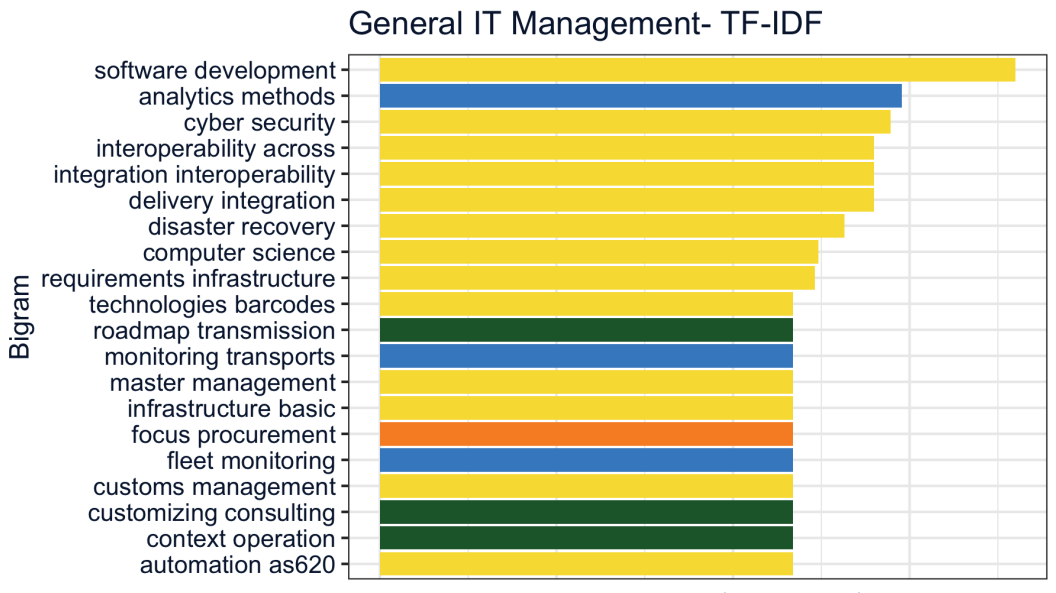

Distinctiveness (low to high)

Taxonomy category
Social, management and leadership skills
Analytical, creative thinking and problem solving skills
Resource management skills
Technical skills

\section{Manufacturing - Process Planning \& Industrial Engineering}

Process Planning \& Industrial Engineering- TF-ID|

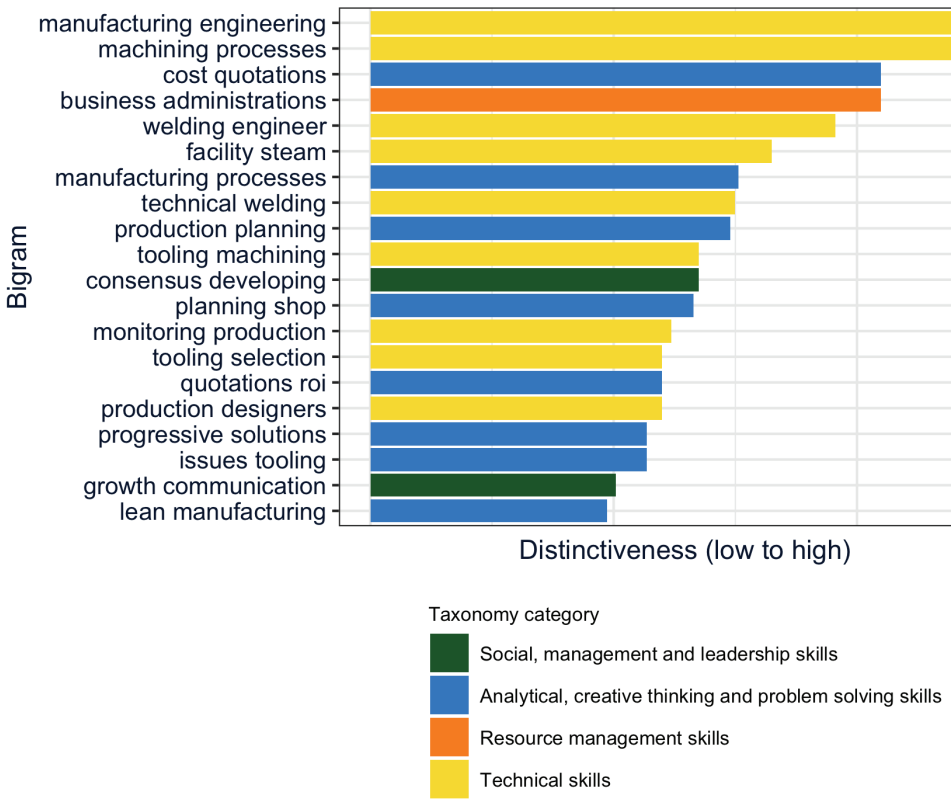





\section{Appendix A: Detailed approach}

\section{Taxonomy}

The aim of this research is to develop a comprehensive taxonomy of the most important skills needed for jobs at a multinational energy company. The company currently has a catalogue with relevant competencies for their jobs, which is very extensive and has overlapping components. Therefore, with the new taxonomy, based on O*NET (see Chapter 2), we aim to create one common language that is future-oriented and company-specific. We aim to make the taxonomy as comprehensive as possible, while at the same time keeping the items generic enough such that they are applicable across the different job-groups and business areas.

There are a number of skills and personality traits that enable a worker to adequately perform a task. These tasks are changing over time due to for example, structural changes, energy transition, etc. Jobs are bundles of tasks that workers are required to perform. In this project, we are looking at skills (developed capacities to perform a job) and personality traits (relatively constant during adulthood, e.g., conscientiousness. Additionally, needed in times of change, resilience). These skills and personality traits are elaborated in this taxonomy.

A widely agreed upon taxonomy does not exist, therefore the taxonomy was created based on the $O^{*} N E T$, which is a scientific source widely used for occupation information. To further develop the taxonomy, we conducted expert-interviews with HR-personnel from the company and each item of their competency catalogue was analyzed. This process resulted in a generic, but company-specific taxonomy.

Text-mining vacancy data the company provided ROA with a corpus (dataset containing the full text of all vacancies) of vacancy data ranging from the first of October 2018 until the 3oth of September 2020. In this data, each row represents one vacancy and contains information about, among others:

- the job (title, description, how many positions are available, contract type, experience level and whether the job results from job growth or a replacement)

- the geographical location (country, city, language) and

- organizational information (job-group, job-sub-group, organization, business unit). 
The data has vacancies for 78 job-sub-groups that all belong to one of the job-groups. To understand the current skills demand, we analyze the job descriptions for each jobsub-group and search for mentions of skills. However, job descriptions are composed of many different types of information, not just skills. In the data, the job descriptions are located in one column and are unstructured. Every description has a different set-up. This makes it challenging to extract the information that is needed. For this reason, a creative approach was needed.

\section{Cleaning}

The data cleaning comprises several steps. First, each vacancy is characterized by a number of openings. We weight the number of vacancies for this number of openings to get a true reflection of the skill demand. If a vacancy has for example 3 job openings, this vacancy will get a weight of 3 in the data. Second, we clean the job descriptions by making all letters lowercase and removing mentions, URLs, emoji, punctuations and numbers that are surrounded by whitespaces (this allows us to keep skills like 3D-printing or office 360 in the corpus). Third, we remove all stop words, any superfluous whitespaces and sentences that are well-known marketing phrases.

Finally, we exclude a number of outliers. These outliers are vacancies that consist of less than 58 characters (based on the cleaned text) in its job description, these fall out of a normal distribution and generally do not have job descriptions that list skills needed for the job. After consulting with the project-team, any vacancies from specific organizations are excluded, since these are not in the scope of this project. Also, we exclude a vacancy that asks for 150 employees, which would affect the data too much.

This leaves us with a total of 9.551 vacancies for 7.950 job openings. The total corpus of text we analyze consists of 2.500 .843 words.

\section{Extracting distinctive terms}

When looking for the necessary skills in a job description, we are generally less interested in the text areas that contain general information about the company, but more interested in the information that is specific to that vacancy. To merely look at how frequent certain words appear in a job description, would be insufficient, since the general information is often similar across multiple vacancies. Figure A.1 shows an example of a vacancy that was analyzed in this project. The red-colored items contain general information that does not list any skills needed to do the job. The rest of the text does contain information that could be classified as skills and will be more unique for every vacancy. The green items are the skills that are extracted by our procedure. Below we explain the rest of the procedure to get to this result. 
Figure A.1 Example vacancy

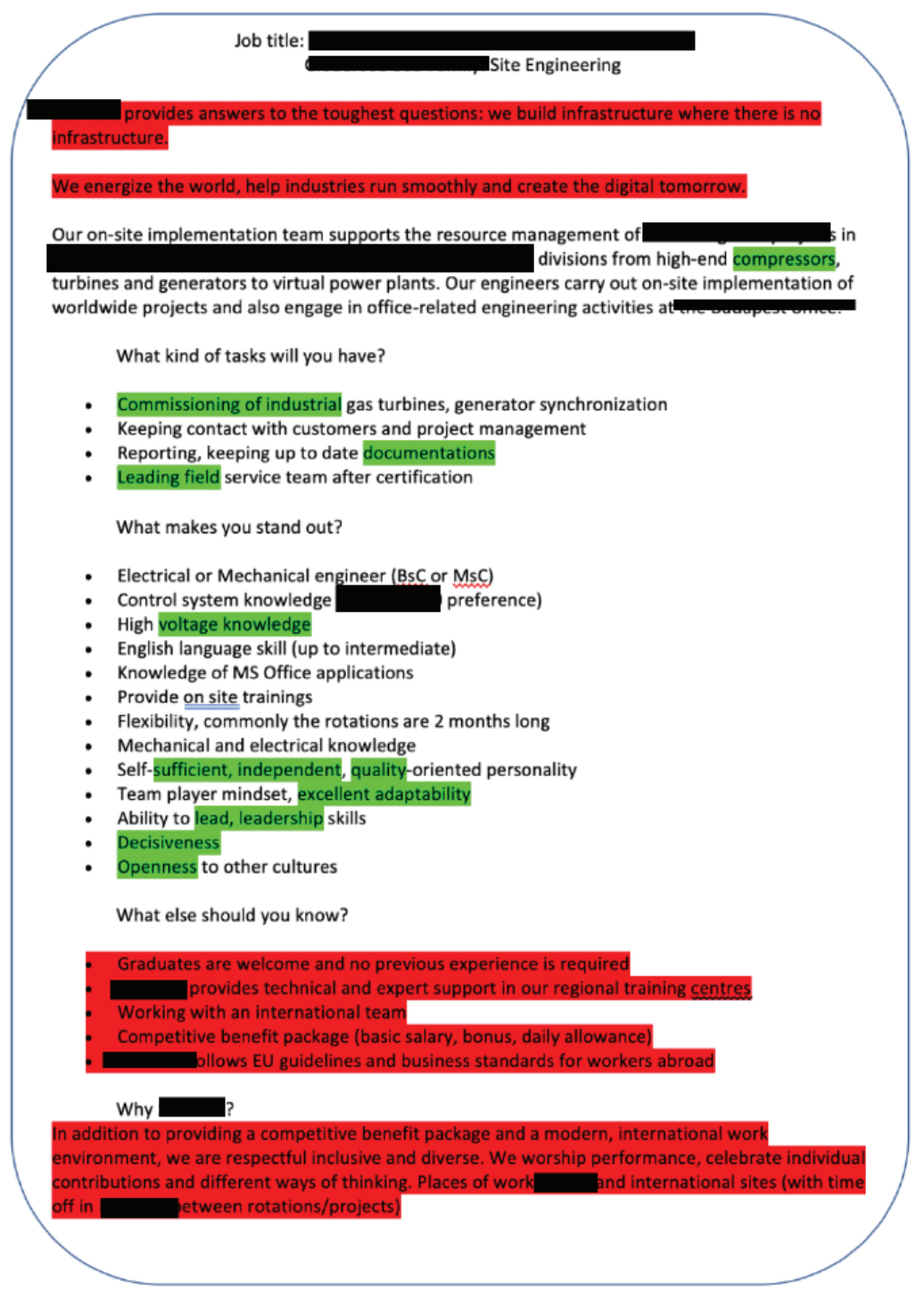

To extract the specific information, we use the statistical measure tf-idf (term frequency - inversed document frequency). This measure identifies how distinctive a term (or rather a bigram, a pair of words, in our case) is to a job-sub-group in the corpus of all job-sub-groups. Tf-idf measures how frequent a term occurs, adjusted for how rarely it's used. This statistic will give a higher value to terms that are more unique to a job-subgroup and a lower value to terms that are common in the entire corpus. 


\section{Emsi Skills}

Now that we can measure how distinctive a certain term is for each job-sub-group, the next step is to further condense these lists. These lists still contain information that would not be classified as a skill. We need to extract the skills and ensure minimum human interaction. To solve this, we use the Emsi Skills list.? Emsi Skills is an initiative from a team of economists and labor market analysts that aims towards using skills as a common language between three parties: potential employees, potential employers and programs looking to connect those two. By analyzing resumes, job descriptions from vacancies and online profiles, Emsi Skills has gathered over 30.000 skills. This extensive list of skills is freely available online via an API.

We use this list combined with the skills we defined in our taxonomy (with its synonyms derived from WordNet, a lexical database created by Princeton University) to create a custom skills-database. Using this skills-database, we extract the terms that were derived from the vacancy texts that have a (at least partial) match with items in the skills database. This results in a filtered list of skills coming directly from the company's job descriptions.

\section{Matching the skills to the taxonomy}

To categorize the skills from the job descriptions to the taxonomy, the top 20 skills for each job-sub-group was manually labelled with one of the main categories of the taxonomy. This labelling was also checked and sometimes adjusted by specialists of each job-sub-group at the company. The results are all presented in graphs such as Figure A.2.

7 https://skills.emsidata.com/ 
Figure A.2 Site Engineering. Top 20 skills with a link to the taxonomy

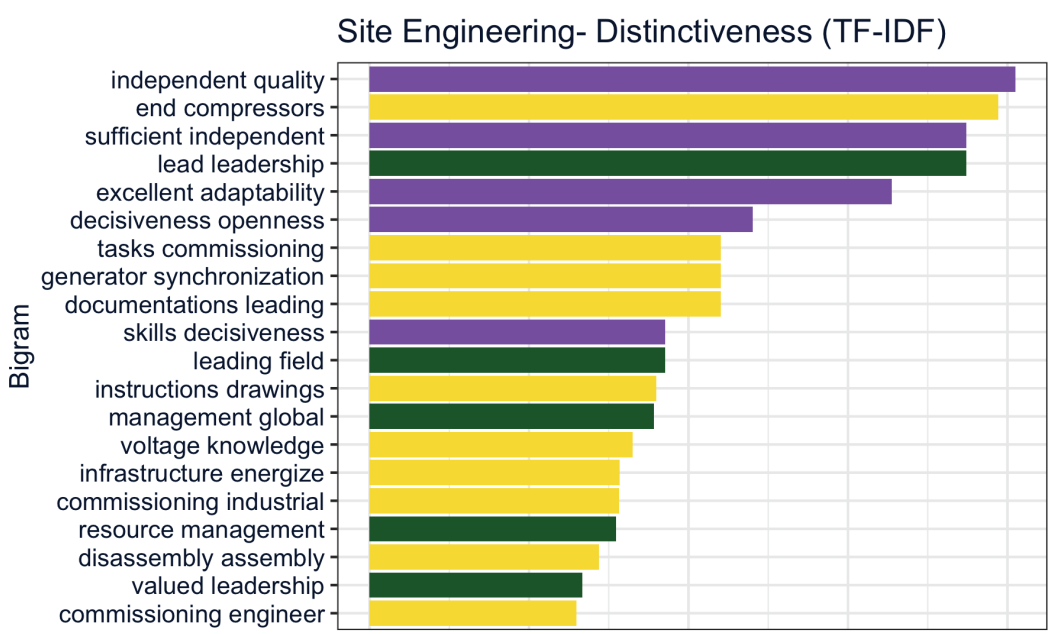

Distinctiveness (low to high)

Taxonomy category

Social, management and leadership skills

Technical skills

Personality traits 



\section{Appendix B: First implementations at the company}

The company is using the output of this research to further tailor it to the company's needs based on the feedback they have received from the representatives of each jobgroup. Figure B.1 displays an overview of taxonomy-wide changes the company made. These changes mainly relate to adjusting the titles of the taxonomy categories.

Figure B.1 Taxonomy-wide changes

\section{Tailoring the research-based Vacancy Analysis result into the Skills Taxonomy}

Vacancy Analysis Skills Taxonomy

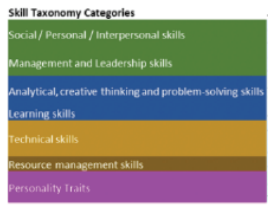

\section{Connection}

Thinking \& Creativity Digital, Technical, Domain Skills Drive

\section{Skills Taxonomy}

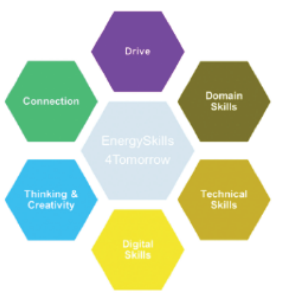

The research-based Skill Taxonomy Categories were reviewed_adjusted and streamlined for use i ed on the feedback of the reviewees.

3 Taxonomy Categories - "Drive", "Connection", "Thinking \& Creativity" were identified as overarching categories.

Those comprise skills that are applicable across

- Social, Interpersonal, Management and Leadership into Connection

- Analytical, Creative Thinking and Problem-Solving Skills with Learning Skills into Thinking \& Creativity

- Technical Skills and Resource Management Skills into Digital, Technical \& Domain Skills

- Personality Traits was renamed into Drive

The company also created a dashboard to inform their employees about the findings of this research and how to use the dashboard to access this information. An example of this dashboard is depicted in figure B.2. 
Figure B.2 Dashboard. Most distinctive skills for each job-group

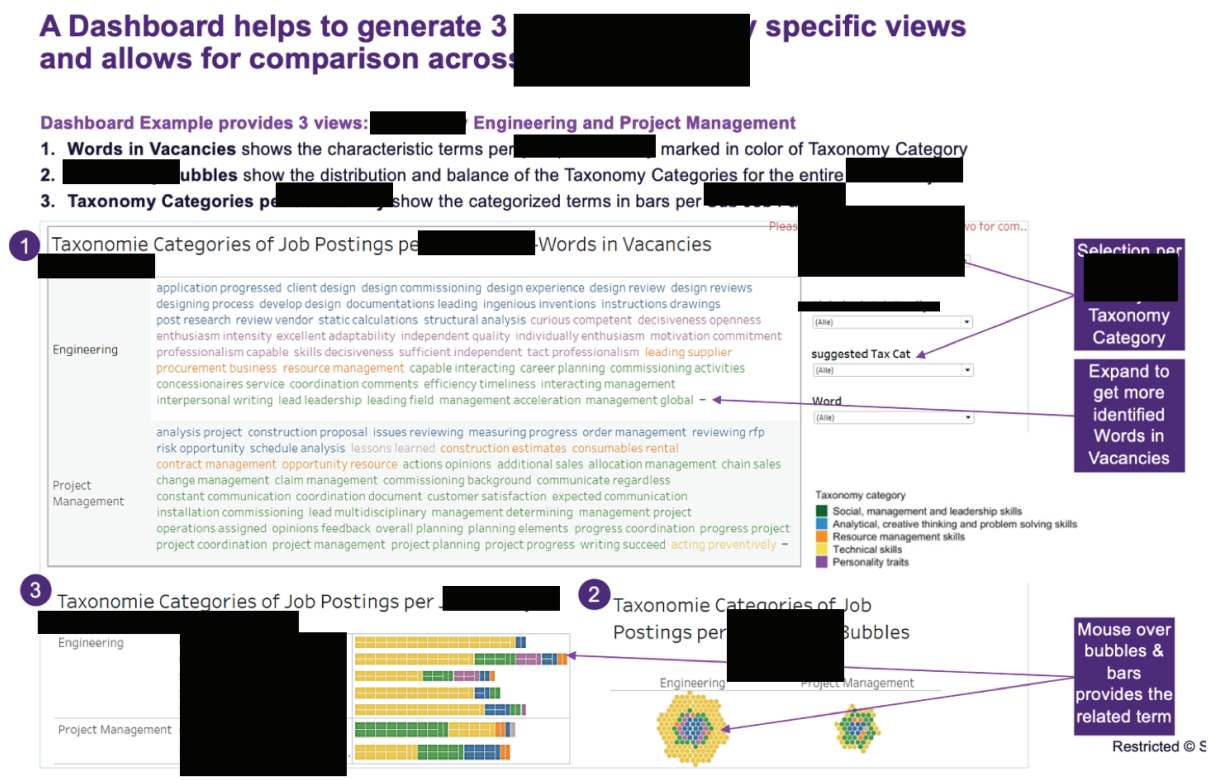

In figure B.3 shows the guide the company created to help interpret the results and motivate (a.o.) HR-personnel to help them use the findings and derive further actions to tackle challenges related to strategic workforce planning. 


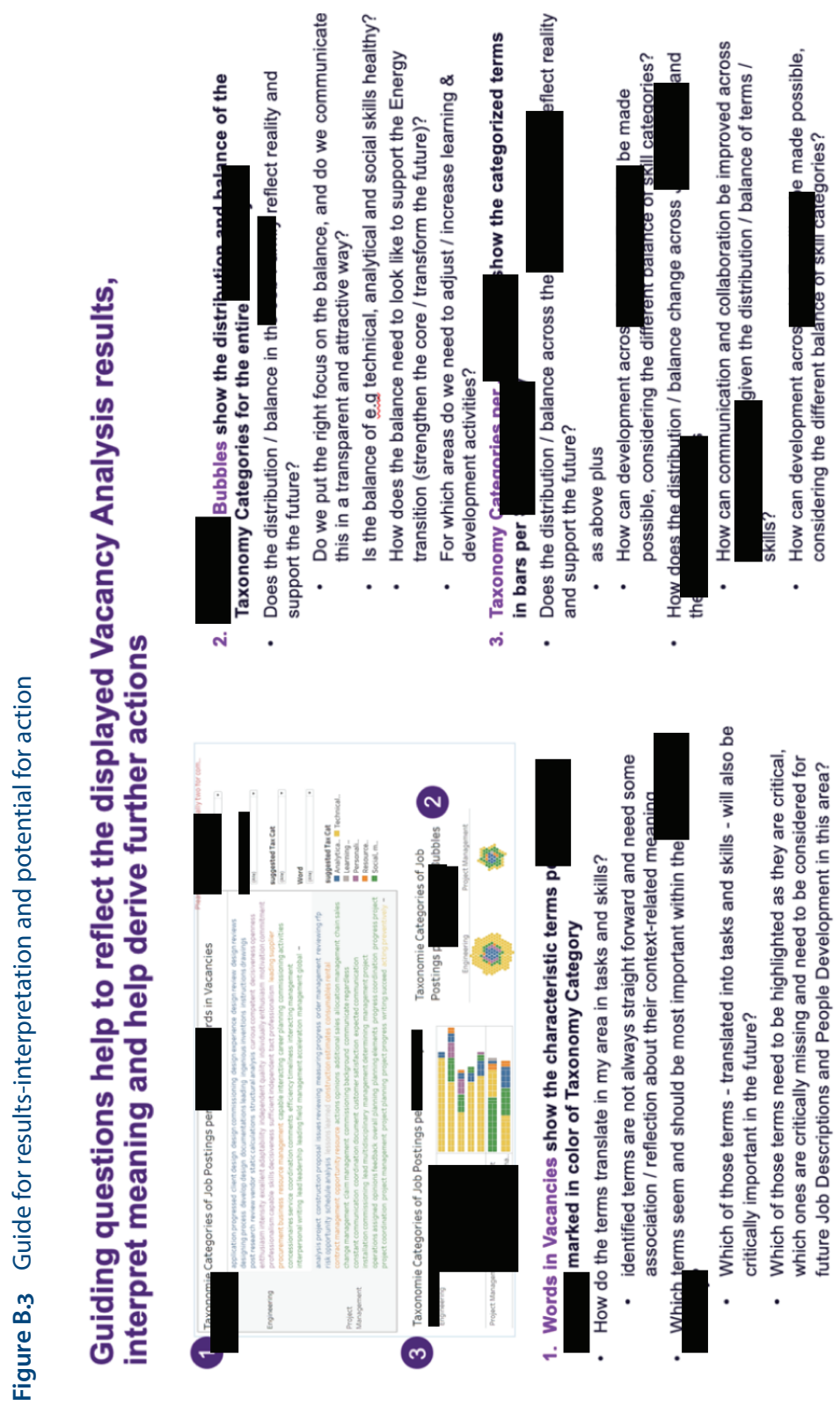


